\title{
Precision-engineered Peptide and Protein Analogs: Establishing a New Discovery Platform for Potent GPCR Modulators
}

\author{
Kalyana Bharati Akondia ${ }^{a}$ Marianne Paolini-Bertrand ${ }^{\mathrm{a}}$, and Oliver Hartley ${ }^{\star a b}$
}

\begin{abstract}
Numerous members of the human G protein-coupled receptor (GPCR) superfamily are receptors of therapeutic interest. GPCRs are considered to be highly tractable for drug discovery, representing the targets of approximately one-third of currently licensed drugs. These successful drug discovery outcomes cover only a relatively small subset of the superfamily, however, and many other attractive receptors have proven to present significant challenges. Among these difficult GPCRs are those whose natural ligands are peptides and proteins. In this review we explain the obstacles faced by GPCR drug discovery campaigns, with particular focus on those related to peptide and protein GPCRs. We describe a novel and promising approach for these targets based on engineering of their natural ligands and describe an integrated discovery platform that allows potent ligand analogs to be discovered rapidly and efficiently. Finally, we present a case study involving the chemokine receptor CCR5 to show that this approach can be used to generate new drugs for peptide and protein GPCR targets combining best-in-class potency with tunable signaling activity.
\end{abstract}

Keywords: Drug discovery $\cdot$ GPCR $\cdot$ Peptide $\cdot$ Protein engineering

\section{GPCRs as Drug Targets}

Human G protein-coupled receptors (GPCRs) are a superfamily of approximately 800 cell surface receptors that respond to a diverse range of stimuli, including photons, ions, small molecules, lipids and polypeptides. ${ }^{[1]}$ GPCRs are key to a similarly broad range of physiological and pathological pathways, and as a consequence they represent a valuable hunting ground for drug discovery. Although the GPCR superfamily has a historical reputation for being highly druggable, with over $30 \%$ of currently licensed drugs targeting GPCRs, a closer look at the targets of these drugs reveals that they cluster around a narrow subset corresponding to approximately $15 \%$ of the superfamily. ${ }^{[2]}$

The remaining $85 \%$ of the superfamily includes both sensory receptors, which are not clearly associated with disease, and orphan GPCRs, for which endogenous ligands and clear roles in physiology and pathology have yet to be defined. ${ }^{[3]}$ Importantly, however, the group also contains GPCR subfamilies that are of clear interest for drug discovery, but which have proven to be of low tractability using established modalities and approaches. ${ }^{[2,4]}$

\section{GPCR Structure and Function}

GPCR drug discovery is founded upon knowledge of receptor structure and function. ${ }^{[5]}$ GPCRs are seven transmembranespanning proteins with an extracellular domain consisting of the $\mathrm{N}$-terminal region of the receptor and three extracellular loops, a transmembrane (TM) domain formed by the seven-helix bundle, and an intracellular domain consisting of three intracellular loops and the C-terminal region of the receptor (Fig. 1A). Molecules that activate the receptor, both the natural ligands and activating drugs that share their binding pocket (known as the orthosteric site, Fig. $1 \mathrm{~B}, \mathrm{C})$, are referred to as agonists, whereas molecules that occupy the orthosteric site without activating it, thereby blocking access by agonists, are referred to as antagonists. For many GPCRs, the TM domain binding pocket contains additional sites (known as allosteric sites, Fig. 1B, C) other than that occupied by the natural ligands, which, when engaged by drugs, can either enhance or reduce the capacity of the receptor to respond to agonists. Drugs of this type are known as positive and negative allosteric modulators, respectively.

GPCR signaling is a consequence of ligand-driven conformational changes at the key trigger sites in the TM domain binding pocket of the receptor, which are then amplified as they are transmitted to the intracellular domain of the receptor, leading to the engagement and activation of cytosolic sensor proteins (including the $\mathrm{G}$ proteins after which the receptors are named) that are responsible for initiating and controlling signal transduction. GPCR signaling can be divided into $\mathrm{G}$ protein-dependent and arrestinmediated (G protein-independent) pathways (Fig. 1D), with certain ligands capable of preferentially activating one pathway over the other. These ligands are known as biased agonists (Fig. 1E).

\section{Obtaining Purified GPCRs for Screening}

The capacity of GPCRs to govern not only whether or not a signal is produced (agonist or antagonist), but also the quantity (partial agonist, allosteric modulator) and the quality (biased agonist) of that signal is due to a high level of structural plasticity, characteristic of CPCRs. ${ }^{[6]}$ This property, which has the advantage of opening possibilities for the identification of fine-tuned GPCR signaling modulator drugs, also presents a challenge to the discovery process related to obtaining sufficient amounts of highly purified and appropriately folded target receptor on which to screen drug libraries. In addition to being difficult to express at high levels, GPCRs are prone to adopting functionally irrelevant conformations once removed from the cellular environment. ${ }^{[7]}$ While progress has been made in enhancing expression and structural stability of GPCRs, ${ }^{[8]}$ the accessibility of target material for discovery programs, both using small molecule or antibody approaches, remains a major bottleneck. ${ }^{[9]}$ 


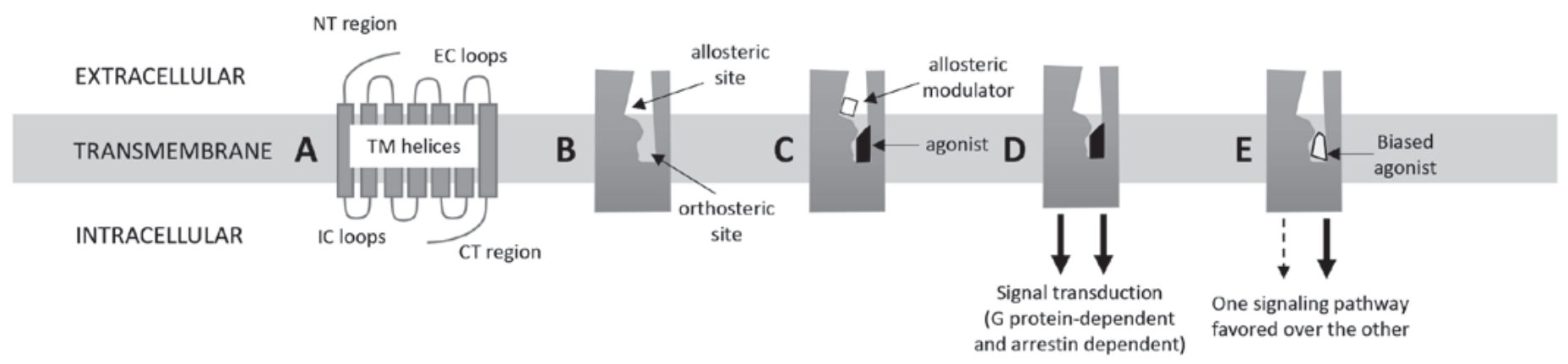

Fig. 1. General principles of GPCR structure and activation. A. GPCR topology: The N-terminal (NT) region and the extracellular (EC) loops of the receptor form the extracellular domain, the seven transmembrane (TM) helices form the transmembrane domain, and the intracellular loops together with the C-terminal region of the receptor form the intracellular domain. B. Simplified schematic illustration of a GPCR indicating allosteric and orthosteric sites. C. Agonists engage the orthosteric site of the receptor, whereas allosteric modulators engage allosteric sites. D. Receptor activation leads to signaling through G protein and arrestin-dependent pathways. E. Biased agonists activate the receptor, favoring one pathway over the other.

\section{Screening not just for Binding but for Function}

Primary screens for GPCR libraries are often based on detection of binding activity of library components. ${ }^{[7 c]}$ Screens of this kind have the disadvantage of requiring further phases of downstream screening using cell-based assays to characterize pharmacological activity. ${ }^{[10]}$ Screening more directly related to functional modulation can be achieved using intact living cells to present the receptor target, and then evaluating the capacity of each library element both to activate signaling and to modulate the signaling activity of the endogenous ligand.[11] Cell-based screening approaches have the additional advantage of bypassing the onerous receptor purification process, and the cellular environment ensures that the receptor remains in physiologically relevant structural conformations. However, they are hampered by the presence at the cell surface of unrelated structures, including endogenous GPCRs. These structures have the potential to provide both irrelevant binding signals in readouts based on receptor interaction and misleading results in functional assays. ${ }^{[7 \mathrm{c}, 12]}$

\section{Binding Pockets: Too big, too small or just right}

An additional challenge to conventional drug discovery approaches is presented by GPCRs whose natural ligands are large peptides and small proteins (Fig. 2). The larger interfaces presented by the binding pockets of these GPCRs are more typical of those of protein-protein interactions, which have long been considered difficult to modulate using small molecules. ${ }^{[13,14]}$ At the same time, they are too small to be fully engaged using antibodies, which generally interact with the extracellular domain of the receptor only. ${ }^{[12]}$ While this provides a means to generate antagonists that sterically block access of natural agonists, finetuning of the signal modulation capacity of the receptor, which requires interaction with the TM domain binding pocket, is difficult to achieve using antibody-based approaches. [12]

Using the natural peptide or protein ligand as a scaffold for GPCR drug discovery means that the starting ligand is already of an appropriate size for the binding pocket: what remains is to modify its shape in order to engineer contacts with the receptor TM domain in order to gain control of both binding affinity and signal transduction capacity.

\section{Peptide and Protein GPCR Ligands have Modular 'Message-address' Structures}

An established characteristic of the natural ligands of peptide and protein GPCRs is a two-site interaction mechanism with the receptor, comprised not only of a 'message' interaction with the TM domain of the receptor that drives receptor activation, but also a high affinity and specificity 'address' interaction with the extracellular domain of the receptor (Fig. 3A). Among the peptide

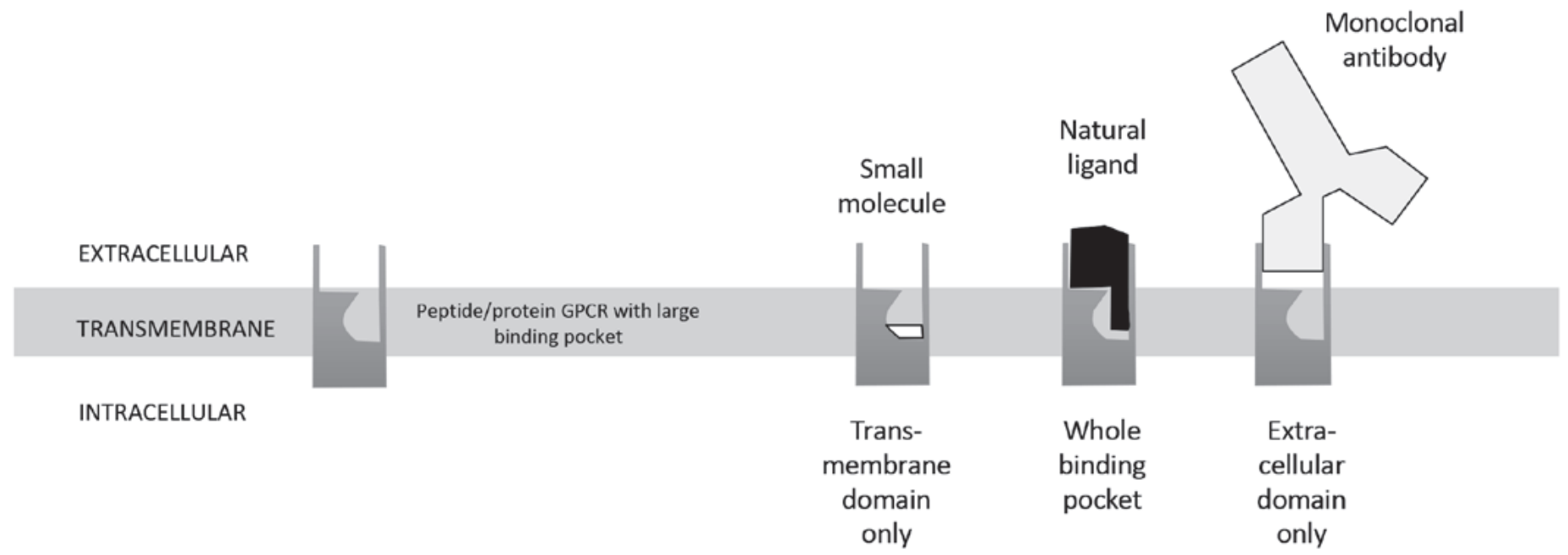

Fig. 2. GPCR drug modalities and the binding pockets of peptide and protein GPCRs. Schematic illustration showing that while small molecules are too small to fully occupy the binding pocket, and antibodies are too large to fully penetrate into it. Natural ligands exhibit a close molecular fit with the binding pocket, and as such represent useful scaffolds for developing drugs that modulate peptide and protein GPCRs. 
and protein receptors that have been shown to exhibit such a twosite binding mechanism are opioid receptors, ${ }^{[15]}$ complement $\mathrm{C} 5 \mathrm{a}$ receptor, ${ }^{[16]}$ chemokine receptors ${ }^{[17]}$ and members of the Class $\mathrm{B}$ GPCR subfamily.[18]

The implication of this two-site binding mechanism for engineering of a peptide or protein ligand is that its 'message' structures can be modified independently of its 'address' structures. Hence a group of 'message' region-modified analogs of a given peptide or protein would retain receptor specificity and differ only in their signal transduction capacity. ${ }^{[17 a]}$ Indeed, in the simplest case, ligands with a truncated TM binding region lose signaling activity but block access of the natural ligands to the receptor, thereby behaving as antagonists. ${ }^{[16,19]}$ More sophisticated modifications to the TM binding region of the ligand can lead not only to changes in both the quantity and quality of signaling activity, but also, via the establishment of additional molecular contacts with the TM domain of the receptor, to significant increases in binding affinity and potency. ${ }^{[20]}$ This provides a clear rationale for engineering ligand analogs to develop new drugs targeting the challenging group of peptide and protein GPCRs (Fig. 3B).

\section{Discovery Strategies for Engineered Analogs}

Potent peptide and protein analogs have been successfully engineered using rational design based on empirical observations, particularly via the introduction into the 'message' region of the ligand of non-natural, non-coded structures in a strategy termed 'protein medicinal chemistry'.[20b] As an increasing number of structures of GPCRs in complex with their natural ligands become available, ${ }^{[21]}$ together with deeper knowledge of the signal triggering mechanisms common to GPCRs, ${ }^{[5 c]}$ structure-guided rational design is likely to play an increasingly important role in peptide and protein-based analog discovery, facilitated by in silico docking studies. ${ }^{[21]}$

At the same time, combinatorial library-based approaches provide a valuable means by which to fully explore the structural space between the ligand and the TM domain of the receptor. By screening libraries of peptide or protein ligands that are modified in their 'message' regions only (i.e. retaining the native 'address' region) it is possible to ensure that all variants retain binding specificity for the target receptor, providing a key advantage in that discovery work can be carried with unpurified receptors in their native environment on intact cells.

Surface display technology provides a means by which vast libraries of ligand variants can be selected by panning on cells expressing the target molecule. ${ }^{[22]}$ When applied to receptors on live cells, panning of this kind selects for ligands with enhanced functional interaction with the receptor, capable of identifying both signaling and non-signaling variants in the same campaign. [23] So far, exemplification of this approach has been limited to the chemokine receptor family, but it would be equally applicable to discovery work on other peptide and protein GPCR families.

\section{Producing Analogs to Assess Pharmacological Activity}

Once a set of analogs has been chosen, either by rational design or via a library screening approach, it is necessary to produce each molecule at sufficient yield and purity to assess its pharmacological properties. Peptides of up to 25 residues in length can generally be accessed at appropriate purity using single-step chemical synthesis, and robust synthetic library-based approaches are available for this size range. ${ }^{[24]}$ However, for the majority of peptide and protein GPCRs, the natural ligands have longer, more complex structures, and their synthesis requires more complex multi-step processes requiring intermediate column chromatography purification steps. ${ }^{[25]}$ While in principle, recombinant methods could be used to generate groups of longer peptides, the expression and purification approaches required are onerous to set up in parallel, and host cell-derived contaminants can interfere with readouts in cell-based assays. Hence parallel production of peptides and small proteins presents a significant technology gap hindering ligand analog-based discovery approaches. To address this, we have recently developed a column-free multiplex synthesis approach that enables hundreds of analogs of a given target peptide or small protein to be produced at a sufficient yield and purity to support discovery campaigns. [26]

\section{Parallel Screening for Binding and Function}

Since in 'message' region-modified variants, signaling activity can be increased or decreased independently of receptor binding affinity, it is logical to use assays to test candidate analogs for both parameters in parallel. Signaling activity on GPCRs can be further subdivided into $\mathrm{G}$ protein-dependent and arrestin-dependent pathways, and by comparing signaling activity between the two pathways it is possible to identify biased agonists. Therefore, for a complete structure-activity exploration, each analog should be assessed not only for binding affinity to the receptor, but also for potency in cell-based assays for $\mathrm{G}$ protein-dependent signaling (based on measurement of second messenger $e . g$. $\mathrm{Ca}^{2+}$ flux) and arrestin-dependent signaling (e.g. arrestin recruitment, receptor downmodulation).

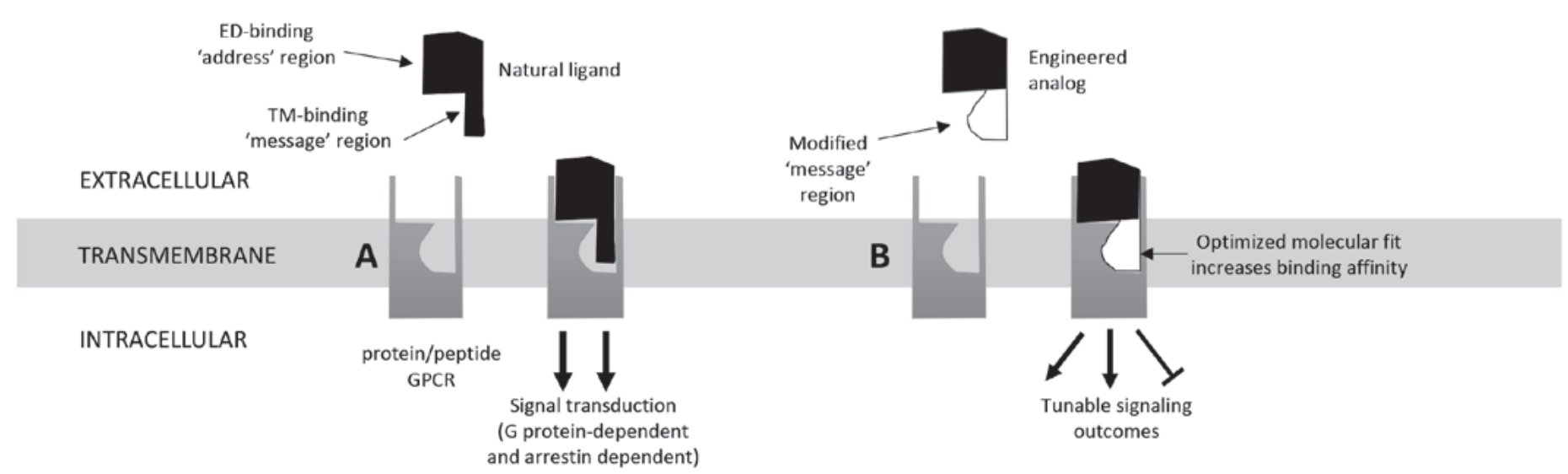

Fig. 3. Precision engineering of the natural ligands of peptide and protein GPCRs as a strategy for drug discovery. Modification of the 'message' region of the natural ligand leads not only to increased binding affinity by improving the molecular fit with the binding pocket, it also allows control to be taken over receptor signaling activity, by modulating contacts with regions in the TM domain that are key to receptor activation. 


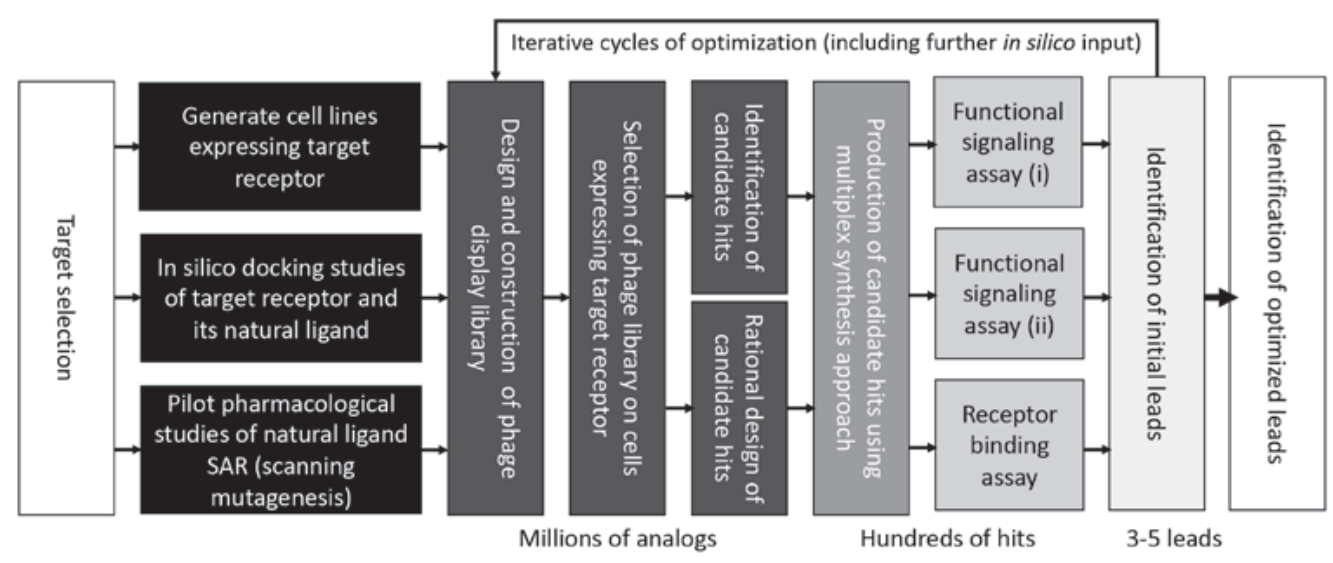

Fig. 4. An integrated platform for discovery of engineered analogs targeting peptide and protein GPCRs.

\section{Developing a Novel Peptide GPCR Discovery Platform}

We have set up a fully integrated platform for the discovery and optimization of analogs of the natural peptide and protein ligands of GPCRs (Fig. 4). When a target receptor has been chosen, cell lines expressing the receptor are produced, together with a pilot series of analogs to explore receptor ligand structure-activity relationships and/or to confirm and extend previously published structure-activity data. The results of these studies are then used to design phage display libraries encoding variants $\left(10^{6}-10^{9}\right)$ of the natural ligand, with diversity focused into the 'message' region of the ligand. The phage libraries are selected by biopanning on cell lines expressing the target receptor, leading to the identification of hundreds of candidate hits, comprised both of sequences of selected phage clones and rationally designed analogs informed by the pilot structure-activity studies. These candidate hits are rapidly produced using the multiplex synthesis approach and tested in parallel in assays using cell lines expressing the target receptor in order to obtain the required structure-activity information.

The multidimensional dataset obtained provides a key advantage, yielding a structure-activity relationship matrix that defines sequence motifs which enhance or impair receptor affinity, as well as those which affect the quantity and quality of signaling activity. These matrices can be used to identify initial leads, refine in silico models of receptor-ligand functional interaction, to inform the design of next-generation phage display libraries for lead optimization.

The speed by which phage library selection can be coupled to candidate hit synthesis and evaluation in this platform means that cycles of iterative improvement can be performed rapidly during lead optimization, with improvements obtained through both screening of new phage libraries and in silico-guided rational design. By performing a series of improvement cycles, it is pos- sible to generate panels of analogs exhibiting not only enhanced potency, but also a full spectrum of signaling activity, from pure antagonists through to superagonists (see case study, below).

\section{Case Study: CCR5}

CCR5 is well-known as the principal HIV coreceptor, and as such is a validated target for HIV therapy and prevention. ${ }^{[27]}$ It is also emerging as an important therapeutic target for cancer ${ }^{[28]}$ as well as neuroinflammation ${ }^{[29]}$ and the COVID-19 associated acute respiratory distress syndrome. ${ }^{[30]}$ We successfully used an analog-based discovery approach to generate potent modulators of CCR5.[20a] In this work, an initial round of discovery was performed using one of the natural CCR5 ligands, CCL5, followed by two cycles of iterative optimization. The discovery phase yielded two initial hits with potency clearly in excess of the natural ligand. Interestingly, one candidate hit was an antagonist while the other showed strong signaling activity. By conducting a first cycle of optimization it was possible to increase potency while continuing to identify both signaling and non-signaling analogs. The second cycle of optimization led to the identification of a range of analogs reaching picomolar potency, including the antagonist OB-002 (previously known as 5P12-CCL5) and the superagonist 6P4-CCL5 (Fig. 5A).

At the same time, a large number of other potent CCR5 modulators were discovered, covering a full spectrum of signaling activity from antagonist to superagonist, as well as certain analogs with potential biased agonist activity (Fig. 5B).

Data from head-to-head CCR5 functional inhibition assays including maraviroc, the only CCR5 inhibitor currently licensed for clinical use, as well as the other most advanced small molecule and mAb inhibitors currently in clinical development, demonstrate that OB-002 is the best-in-class CCR5 inhibitor in
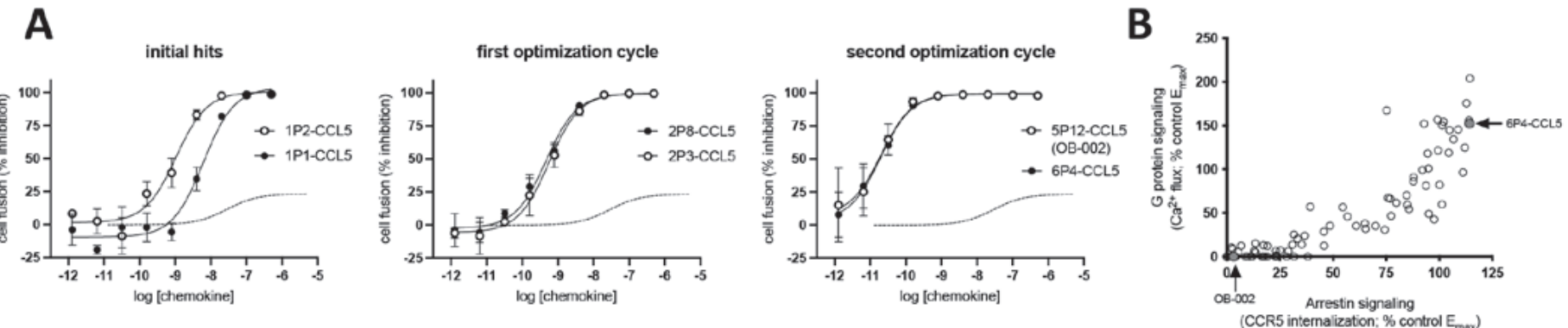

Fig. 5. Discovery of potent modulators of the chemokine receptor CCR5. A. Over three successive cycles of discovery and optimization it was possible to progressively improve anti-HIV potency with respect to that of the parent molecule (dashed line). At each stage of the process, both full antagonists (filled circles) and full agonists (open circles) were identified (Data from ref. [20a]). B. Plot showing G protein and arrestin pathway signaling activity with each point representing activity of a different potent modulator discovered during the campaign (Data from ref. [26]). The ensemble of analogs covers an entire spectrum of signaling activity and those lying outside of the main diagonal axis represent potential biased ligands 
A

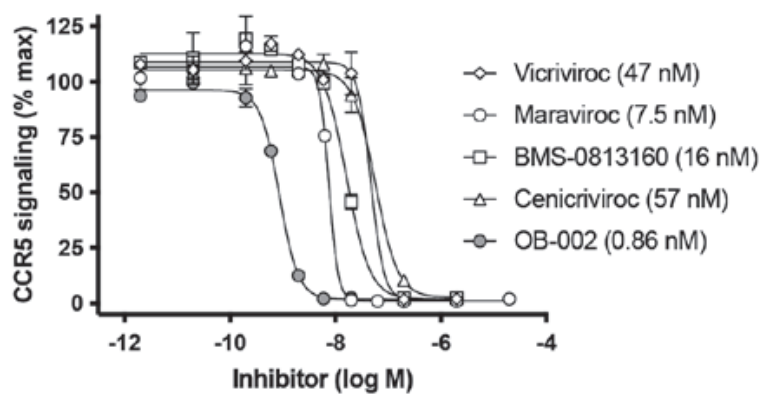

B

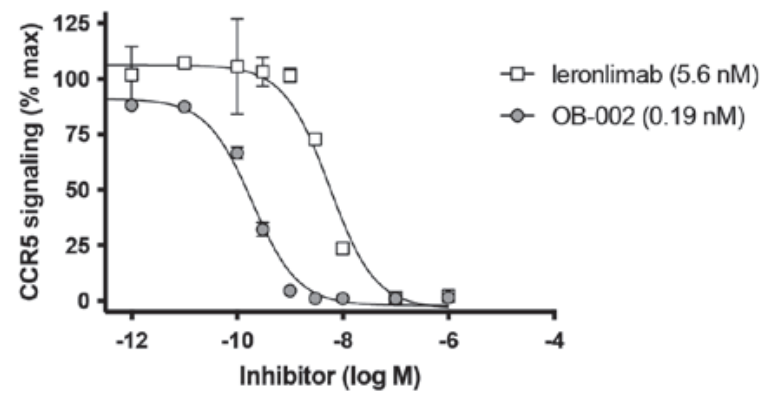

Fig. 6 OB-002 is the best-in-class CCR5 inhibitor. Dose-response curves comparing the potency of OB-002 with a range of small molecule CCR5 inhibitors (A) and an anti-CCR5 mAb in clinical development (B). Data obtained by Orion Biotechnology from assays performed by Euroscreen Fast (euroscreenfast.com).

terms of in vitro potency (Fig. 6). A gel formulation of OB-002, developed for HIV prevention ${ }^{[31]}$ has completed Phase 1 clinical evaluation. ${ }^{[32]}$ OB-002 has also shown significant efficacy following systemic administration in an animal model of neuroinflammation ${ }^{[33]}$ and is currently in clinical development as a novel form of cancer immunotherapy.

Structural studies of 5P7-CCL5, ${ }^{[34]}$ another highly potent CCR5 antagonist identified in the discovery campaign, and the superagonist 6P4-CCL5, ${ }^{[35]}$ provide structural validation of the analog-based discovery approach, demonstrating how engineering of the 'message' region of the ligand leads to increased molecular contacts with the receptor that enhance potency, as well as modification of key contacts with signaling switch structures in the receptor TM domain that provide the basis for controlling receptor signaling activity.

\section{Conclusion}

Work on CCR5 led to identification and clinical development of a best-in-class GPCR inhibitor, in addition to a range of additional potent modulators of the target receptor lying across a full spectrum of signaling activity. This provides validation of both the approach of using precision-engineered ligand analogs to target peptide and protein GPCRs, and the platform that has been developed to facilitate their efficient discovery. We anticipate that further use of the platform will lead to broader exemplification of its utility to identify high promising drug candidates targeting the challenging but valuable group of peptide and protein GPCRs.

\section{Acknowledgements}

We gratefully acknowledge funding from the Swiss National Science Foundation (grant 184828).

Received: April 23, 2021

[1] M. Vass, A. J. Kooistra, D. Yang, R. C. Stevens, M.-W. Wang, C. de Graaf, Trends Pharmacol. Sci. 2018, 39, 494, https://doi.org/10.1016/j.tips.2018.02.004.

[2] A. S. Hauser, M. M. Attwood, M. Rask-Andersen, H. B. Schiöth, D. E. Gloriam, Nat. Rev. Drug Discov. 2017, 16, 829, https://doi.org/10.1038/nrd.2017.178.

[3] A. S. Hauser, D. E. Gloriam, H. Bräuner-Osborne, S. R. Foster, $B r . J$. Pharmacol. 2020, 177, 961, https://doi.org/10.1111/bph.14950.

[4] D. Wacker, R. C. Stevens, B. L. Roth, Cell 2017, 170, 414, https://doi.org/10.1016/j.cell.2017.07.009.

[5] a) V. Katritch, V. Cherezov, R. C. Stevens, Annu. Rev. Pharmacol. Toxicol. 2013, 53, 531, https://doi.org/10.1146/annurev-pharmtox-032112-135923; b) A. Manglik, A. C. Kruse, Biochemistry 2017, 56, 5628, https://doi.org/10.1021/acs.biochem.7b00747; c) D. Hilger, M. Masureel, B. K. Kobilka, Nat. Struct. Mol. Biol. 2018, 25, 4, https://doi.org/10.1038/s41594-017-0011-7

[6] A. Manglik, B. Kobilka, Curr. Opin. Cell Biol. 2014, 27, 136, https://doi.org/10.1016/j.ceb.2014.01.008.
[7] a) M. Martí-Solano, D. Schmidt, P. Kolb, J. Selent, Drug Discov. Today 2016, 21, 625, https://doi.org/10.1016/j.drudis.2016.01.009; b) N. R. Latorraca, A. J. Venkatakrishnan, R. O. Dror, Chem. Rev. 2017, 117, 139, https://doi.org/10.1021/acs.chemrev.6b00177; c) E. A. Yasi, N. S Kruyer, P. Peralta-Yahya, Curr. Opin. Biotechnol. 2020, 64, 210, https://doi.org/10.1016/j.copbio.2020.06.004.

[8] a) A. Manglik, B. K. Kobilka, J. Steyaert, Annu. Rev. Pharmacol. Toxicol. 2017, 57, 19, https://doi.org/10.1146/annurev-pharmtox-010716-104710; b) E. Ghosh, P. Kumari, D. Jaiman, A. K. Shukla, Nat. Rev. Mol. Cell Biol. 2015, 16, 69, https://doi.org/10.1038/nrm3933; c) C. Klenk, J. Ehrenmann, M. Schütz, A. Plückthun, Sci. Rep. 2016, 6, 21294, https://doi.org/10.1038/srep21294.

[9] J. D. Hothersall, A. Y. Jones, T. R. Dafforn, T. Perrior, K. L. Chapman, Drug Discov. Today 2020, 25, 1944, https://doi.org/10.1016/j.drudis.2020.08.006.

[10] P. Kumari, E. Ghosh, A. K. Shukla, Trends Mol. Med. 2015, 21, 687, https://doi.org/10.1016/j.molmed.2015.09.002.

[11] Q. Ma, L. Ye, H. Liu, Y. Shi, N. Zhou, Exp. Opin. Drug Discov. 2017, 12, 511, https://doi.org/10.1080/17460441.2017.1303473.

[12] C. J. Hutchings, M. Koglin, W. C. Olson, F. H. Marshall, Nat. Rev. Drug Discov. 2017, 16, 787, https://doi.org/10.1038/nrd.2017.91.

[13] J. A. Wells, C. L. McClendon, Nature 2007, 450, 1001 https://doi.org/10.1038/nature06526.

[14] a) A. Ranganathan, P. Heine, A. Rudling, A. Plückthun, L. Kummer, J. Carlsson, ACS Chem. Biol. 2017, 12, 735, https://doi.org/10.1021/acschembio.6b00646; b) A. Sawyer, Biotechniques 2020, 69, 239, https://doi.org/10.2144/btn-2020-0134.

[15] B. E. Krumm, R. Grisshammer, Front. Pharmacol. 2015, 6, 48 , https://doi.org/10.3389/fphar.2015.00048

[16] S. J. Siciliano, T. E. Rollins, J. DeMartino, Z. Konteatis, L. Malkowitz, R. G. Van, S. Bondy, H. Rosen, M. S. Springer, Proc. Natl Acad. Sci. USA 1994, 91, 1214, https://doi.org/10.1073/pnas.91.4.1214

[17] a) T. N. Wells, C. A. Power, M. Lusti-Narasimhan, A. J. Hoogewerf, R. M. Cooke, C. W. Chung, M. C. Peitsch, A. E. Proudfoot, J. Leukoc. Biol. 1996, 59, 53, https://doi.org/10.1002/jlb.59.1.53; b) I. Kufareva, C. L. Salanga, T. M. Handel, Immunol. Cell Biol. 2015, 93, 372, https://doi.org/10.1038/icb.2015.15.

[18] D. Wootten, L. J. Miller, Annu. Rev. Pharmacol. Toxicol. 2020, 60, 89, https://doi.org/10.1146/annurev-pharmtox-010919-023301.

[19] F. Arenzana-Seisdedos, J. L. Virelizier, D. Rousset, I. Clark-Lewis, P. Loetscher, B. Moser, M. Baggiolini, Nature 1996, 383, 400, https://doi.org/10.1038/383400a0.

[20] a) H. Gaertner, F. Cerini, J. M. Escola, G. Kuenzi, A. Melotti, R. Offord, I. Rossitto-Borlat, R. Nedellec, J. Salkowitz, G. Gorochov, D. Mosier, O. Hartley, Proc. Natl Acad. Sci. USA 2008, 105, 17706, https://doi.org/10.1073/pnas.0805098105; b) O. Hartley, H. Gaertner, J. Wilken, D. Thompson, R. Fish, A. Ramos, C. Pastore, B. Dufour, F. Cerini, A. Melotti, N. Heveker, L. Picard, M. Alizon, D. Mosier, S. Kent, R. Offord, Proc. Natl Acad. Sci. USA 2004, 101, 16460, https://doi.org/10.1073/pnas.0404802101.

[21] M. Congreve, C. de Graaf, N. A. Swain, C. G. Tate, Cell 2020, 181, 81, https://doi.org/10.1016/j.cell.2020.03.003.

[22] A. M. Davis, A. T. Plowright, E. Valeur, Nat. Rev. Drug Discov. 2017, 16 681, https://doi.org/10.1038/nrd.2017.146.

[23] K. Dorgham, F. Cerini, H. Gaertner, A. Melotti, I. RossittoBorlat, G. Gorochov, O. Hartley, Meth. Enzymol. 2016, 570, 47, https://doi.org/10.1016/bs.mie.2015.09.014.

[24] a) A. Henninot, J. C. Collins, J. M. Nuss, J. Med. Chem. 2018, 61, 1382 https://doi.org/10.1021/acs.jmedchem.7b00318; b) P. Vlieghe, V. Lisowski, J. Martinez, M. Khrestchatisky, Drug Discov. Today 2010, 15, 40, 
https://doi.org/10.1016/j.drudis.2009.10.009; c) F. Breitling, A. Nesterov, V. Stadler, T. Felgenhauer, F. R. Bischoff, Mol. Biosys. 2009, 5, 224, https://doi.org/10.1039/b819850k.

[25] A. C. Conibear, E. E. Watson, R. J. Payne, C. F. Becker, Chem. Soc. Rev. 2018, 47, 9046, https://doi.org/10.1039/C8CS00573G

[26] M. Paolini-Bertrand, F. Cerini, E. Martins, I. Scurci, O. Hartley, J. Biol. Chem. 2018, 293, 19092, https://doi.org/10.1074/jbc.RA118.004370.

[27] I. Scurci, E. Martins, O. Hartley, Cytokine 2018, 109, 81, https://doi.org/10.1016/j.cyto.2018.02.018.

[28] D. Aldinucci, C. Borghese, N. Casagrande, Cancers (Basel) 2020, 12, https://doi.org/10.3390/cancers12071765.

[29] G. Martin-Blondel, D. Brassat, J. Bauer, H. Lassmann, R. S. Liblau, Nat. Rev. Neurol. 2016, 12, 95, https://doi.org/10.1038/nrneurol.2015.248.

[30] B. K. Patterson, H. Seethamraju, K. Dhody, M. J. Corley, K. Kazempour, J. Lalezari, A. P. S. Pang, C. Sugai, E. Mahyari, E. B. Francisco, A. Pise, H. Rodrigues, H. L. Wu, G. M. Webb, B. S. Park, S. Kelly, N. Pourhassan, A. Lelic, L. Kdouh, M. Herrera, E. Hall, B. N. Bimber, M. Plassmeyer, R. Gupta, O. Alpan, J. A. O’Halloran, P. A. Mudd, E. Akalin, L. C. Ndhlovu, J. B. Sacha, Int. J. Infect. Dis. 2021, 103, 25, https://doi.org/10.1016/j.ijid.2020.10.101.

[31] R. S. Veazey, B. Ling, L. C. Green, E. P. Ribka, J. D. Lifson, M. Piatak, Jr., M. M. Lederman, D. Mosier, R. Offord, O. Hartley, J. Infect. Dis. 2009, 199, 1525, https://doi.org/10.1086/598685.

[32] I. McGowan, N. Tzakis, B. Kosak, B. Korczak, J. Engstrom, M. Tomaszewska-Kiecana, O. Hartley, AIDS Res. Human Retroviruses 2021, https://doi.org/10.1089/aid.2021.0010
[33] K. Steinbach, I. Vincenti, K. Egervari, M. Kreutzfeldt, F. van der Meer, N. Page, B. Klimek, I. Rossitto-Borlat, G. Di Liberto, A. Muschaweckh, I. Wagner, K. Hammad, C. Stadelmann, T. Korn, O. Hartley, D. D. Pinschewer, D. Merkler, Sci. Translat. Med. 2019, 11, https://doi.org/10.1126/scitranslmed.aav5519.

[34] Y. Zheng, G. W. Han, R. Abagyan, B. Wu, R. C. Stevens, V. Cherezov, I. Kufareva, T. M. Handel, Immunity 2017, 46, 1005, http://dx.doi.org/10.1016/j.immuni.2017.05.002.

[35] P. Isaikina, C.-J. Tsai, N. Dietz, F. Pamula, A. Grahl, K. N. Goldie, R. GuixàGonzález, C. Branco, M. Paolini-Bertrand, N. Calo, F. Cerini, G. F. X. Schertler, O. Hartley, H. Stahlberg, T. Maier, X. Deupi, S. Grzesiek, Science Adv. 2021, 7, eabg8685, http://dx.doi.org/10.1126/sciadv.abg8685

\section{License and Terms}

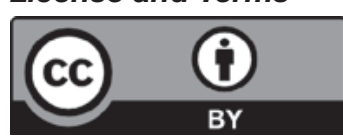

This is an Open Access article under the terms of the Creative Commons Attribution License CC BY 4.0. The material may not be used for commercial purposes.

The license is subject to the CHIMIA terms and conditions: (http:// chimia.ch/component/sppagebuilder/?view=page $\& i d=12$ ).

The definitive version of this article is the electronic one that can be found at https://doi.org/10.2533/chimia.2021.489 